THE BOSTON SOCIETY OF PSYCHIATRY AND NEUROLOGY

October 15,1908

The President, Dr. C. W. PAge in the Chair

\title{
A CASE OF WORD DEAFNESS WITH INTELLECTUAL DEFECT
}

By E. W. Taylor, M.D.

The following case was reported because of the difficulty in diagnosis, the unusual mental state and the exceptional character of the isolated aphasic disturbance. The paticnt was a minister, 52 years old, of a high degree of cultivation. For some years a certain difficulty in the use of language had been noticed, gradual in onset, which with the development of unusual behavior had led to the necessity of giving up his work which was of a very active sort in a missionary field. When first examined the patient presented the contradictory appearance of alertness, together with a curious incapacity in conversation, which suggested dementia. His language also, which was fluent, ran particularly on certain topics unrelated to the questions which were being discussed, and there was also a definite failure of apprehension of the condition in which he then was. He was for example possessed with the idea that his physician was able to secure him a university position in which he might teach Latin and Greek. This idea it seemed almost impossible to eradicate. He resisted physical examination, maintaining that he was well and simply wanted a teaching position. Intellectual tests showed a defect out of all proportion to his general appearance of alertness. Further investigation at many subsequent visits proved that he was almost totally word deaf and that it was impossible to convey one's meaning through spoken words. This explained the fact that questions asked were never properly answered. It became apparent that in order to cover his inability to understand he had formed the habit of discussing wholly irrelevant subjects with the apparent idea that he could thus deceive those with whom he was talking. Tests for aphasia elaborately carried out showed no other sign of defect than pure word deafness, except a certain incapacity readily to understand written language. His speech was voluble and not paraphasic. His eyesight so far as ascertainable was unimpaired. He wrote with great readiness and perfect correctness of spelling and punctuation long statements vaguely intelligible. His quickness of apprehension when he could be made to understand was equally remarkable. Elaborate computations, for example, were done with perfect correctness. The following is a sample of this method of expression:

"Well suppose I go on Thursday afternoon and I will read Latin and Greek but I will be in cooperation with Virgil and Iliad and I will read some lines and paragraphs. Perhaps I am not a professor, but you can make me an assistant tutor, and I like classics-and I had just Honor Classics in the standard to Dalhousie College."

It was not possible to determine any objective cause for the symptoms. There was no marked arteriosclerosis nor was there evidence of softening 
or tumor. The etiology therefore remains obscure. His subsequent history is not definitely known, but so far as can be learned he has not improved.

Dr. Abbot said the case seemed to him very suggestive of arteriosclerotic dementia of not vcry rapid progress. The early symptoms, resembling somewhat those of general paralysis, are significant; and the tendency to repetition of a word or phrase, such as this case showed, is not at all uncommon. If it is a case of arteriosclerotic dementia, what we may call the physiological locus of chief defect-auditory deafnessis very interesting.

Dr. Goss said that Dr. Taylor's case rcminded him of one that came under his observation last spring. A young man was thrown from an electric car striking on his head. He was taken up unconscious, taken to the City Hospital, and remained unconscious about two weeks. Diagnosis: fracture of the base of the skull.

About six weeks later he was committed to the Taunton Insane Hospital as insane. He was found to be totally deaf in both ears, and to all written questions he gave utterly irrelevant answers. In a few days he gave correct answers to all questions written in capital letters, but irrelevant answers to questions written in script.

Repeated examinations revealed the following condition: Some days he gave irrelevant answers to all questions written in capitals or script. Other days he gave correct answers to questions written in capitals, but irrelevant answers to all questions written in script. On still other days he gave correct answers to all questions written in capitals or script.

In about a month he was discharged from the hospital. About a week later he visited the hospital and paid his bill; said that he was feeling all right. About three weeks later he suddenly became comatose, and was taken to the City Hospital where he died two days later. Autopsy revealed fracture of the base of the skull with meningitis.

\section{ARTERIOSCLEROSIS IN A YOUNG MAN}

\section{By G. L. Walton, M.D.}

Dr. Walton reported the following case of arteriosclerosis at $29 \mathrm{yrs}$. A young man of 29, patient of Dr. Harding, became rather suddenly aphasic the last of March. He had had no prior epileptiform or apoplectiform attacks and no change of disposition, no extravagant ideas or other mental disturbance. There was no history or evidence of syphilis. The aphasia was sensory. He could not understand commands more complicated than to shut the eyes or show the tongue. He could not read either aloud or to himself. The urine was r.or8, slight trace of albumin; the heart dullness was increased to the left; the blood pressure was over 180 , the arteries were prominent and hard.

The aphasia gradually increased and other head symptoms appeared. On April I2 he was stupid, and the grasp was weak on the right. Incontinence of urine now appeared. The temperature was 102. ${ }^{\circ}$, dropping the next day to $\mathrm{roI}^{\circ}$. The stupor gradually deepened and death followed. 